\title{
IDENTIFIKASI LETAK DAN KEDALAMAN CRACKS PADA BIDANG LONGSOR MENGGUNAKAN METODE RESISTIVITAS 2D KONFIGURASI WENNER-SCHLUMBERGER STUDI KASUS KECAMATAN SELOREJO, BLITAR
}

\author{
Arin Dwi Agustin, Widya Utama, Juan Pandu G. N. R \\ Jurusan Teknik Geofisika, FTSP Institut Teknologi Sepuluh Nopember \\ e-mail: arindwi11@gmail.com
}

\begin{abstract}
Abstrak. Bencana tanah longsor merupakan bencana alam yang sering terjadi di Indonesia, terutama pada daerah yang memiliki kelerengan yang cukup curam. Berdasarkan peta gerakan tanah Kabupaten Blitar yang dikeluarkan oleh Kementrian ESDM pada bulan Oktober 2016, kawasan penelitian yang berada di Kecamatan Selorejo memiliki potensi gerakan tanah menengah. Salah satu faktor yamg mempengaruhi kestabilan lereng adalah adanya cracks yang terbentuk di bawah permukaan. Ketika cracks dalam lereng terinfiltrasi oleh air hujan, maka akan menjadi proses water prressure built up pada lereng yang menyebabkan lereng tidak stabil. Salah satu metode geofisika yang dapat mendeteksi keberadaan cracks adalah metode geolistrik. Dengan metode ini akan diketahui daerah yang memiliki kandungan air tinggi yang ditunjukkan dengan nilai resistivitas yang rendah. Pada penelitian ini, dilakukan pengukuran tentang perilaku cracks pada lereng ketika sebelum dan sesudah hujan. Setelah dilakukan pengukuran terhadap 6 lintasan, didapatkan hasil bahwa cracks memiliki rentang nilai resistivitas sekitar $0.1-30 \Omega \mathrm{m}$ dengan kedalaman sekitar 3 meter.
\end{abstract}

Kata Kunci: cracks; longsor; resistivitas

\begin{abstract}
Landslide is frequent natural disasters in Indonesia, especially in areas that have a fairly steep slope. Based on ground movement map by the Ministry of Energy and Mineral Resources in October 2016, the research area in Selorejo has medium potential ground movement. One of the factors affecting slope stability is cracks that form below the surface. When cracks in the slope infiltrated by rainwater, it will be a process named water pressure built up on the slope that led the slopes stabilty. One of the geophysical method that can detect the presence of cracks is geoelectric method. With this method will be known areas that have a high water content which is indicated by low resistivity values. In this study, measurement of the behavior of cracks on the slopes when before and after the rain. After measurement of the 6 lines, showed that the cracks have range of values of resistivity of about $0.1-30 \Omega m$ with depth about 3 meters. The main lithology in this area is clay.
\end{abstract}

Keywords: cracks; landslide; resistivity

\section{PENDAHULUAN}

Tanah longsor adalah suatu gerakan menuruni lereng oleh massa tanah dan atau batuan penyusun lereng. Pergerakan tanah dapat diketahui dengan tanda-tanda seperti munculnya retak tarik dan kerutan di permukaan lereng, miringnya pepohonan, hilangnya kelurusan fondasi bangunan dan lainnya (Hardiyatmo, 2012).

Kabupaten Blitar merupakan salah satu kawasan di Jawa Timur dengan kondisi geologi berupa pegunungan vulkanik pada bagian Utara dan bagian Selatan merupakan dataran rendah (PPID Kab. Blitar). Berdasarkan data BPBD Kabupaten Blitar tahun 2015, telah terjadi peristiwa tanah longsor sebanyak 10 kali. Salah satu Kecamatan yang rawan tanah longsor merupakan Kecamatan Selorejo dengan tingkat gerakan tanah menengah (Pusat Vulkanologi dan Mitigasi Bencana Geologi, 2016).

Salah satu penyebab terjadinya peristiwa tanah longsor adalah adanya retakan (cracks) dalam tanah. Dengan adanya cracks, air hujan yang masuk akan menambah beban lereng sehingga mempercepat proses terjadinya bencana tanah longsor.

Metode gofisika yang mampu mendeteksi adanya cracks adalah metode resistivitas, dimana dengan metode ini zona yang memiliki kandungan air jenuh dapat dijadikan acuan tentang adanya cracks dalam tanah. 


\section{TINJAUAN PUSTAKA}

\section{Geologi Regional}

Wilayah Kabupaten Blitar terbagi menjadi dua wilayah yaitu wilayah Utara dan Selatan yang dipisahkan oleh Sungai Brantas. Pada wilayah Selatan, memiliki topografi sebagian besar wilayah perbukitan dan pada daerah sekitar aliran Sungai Brantas memiliki topografi sedikit landai. Daerah penelitian termasuk dalam wilayah Utara, dimana kemiringan lereng $2 \%$ - 40\% dengan kondisi wilayah bergelombang sampai dengan berbukit. Hal ini dikarenakan pada wilayah Utara merupakan bagian dari Gunung Kelud dan Gunung Butak (RPJMD Kabupaten Blitar 2011-2016).

Daerah penelitian berada di Dusun Dawung, Desa Olak-Alen, Kecamatan Selorejo Blitar. Berdasarkan peta geologi lembar Blitar yang dibuat oleh M.Z Sjarifudin dan S. Hamidi pada tahun 1992, daerah penelitian termasuk dalam formasi endapan vulkanik Gunung Butak dengan jenis batuan penyusun lava, breksi gunungapi, tuff breksi dan tuff pasiran.

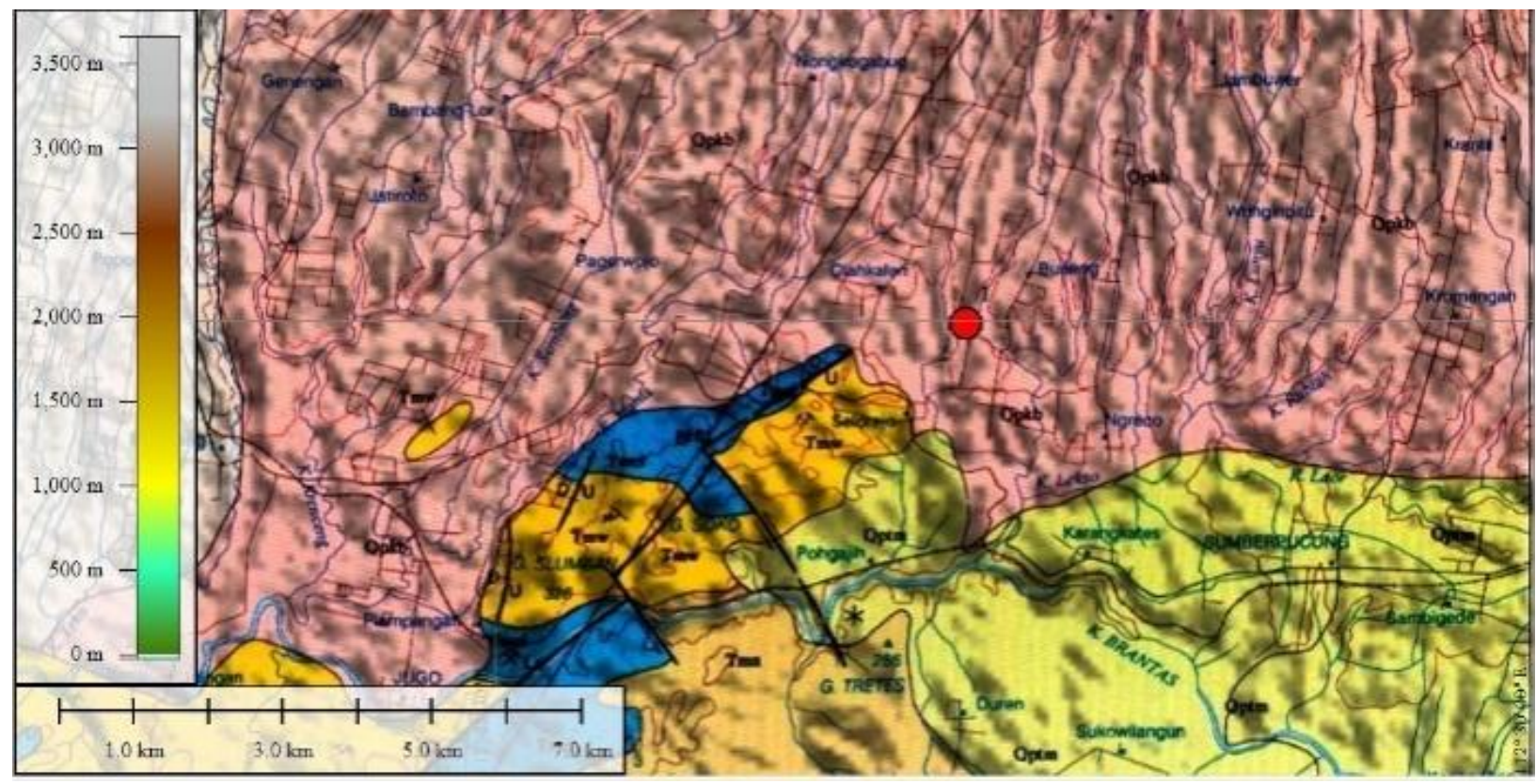

Gambar 1. Kondisi Geologi Daerah Penelitian.

\section{Metode Resistivitas 2D Konfigurasi Wenner- Schlumberger}

Menurut Loke (1999) konfigurasi WennerSchlumberger adalah penggabungan antara konfigurasi Schlumberfger yang sensitif terhadap penetrasi secara vertikal dengan konfigurasi Wenner yang baik secara horizontal. Konfigurasi ini menggunakan sistem aturan spasi yang konstan dengan catatan faktor pembanding " $n$ " yang merupakan perbandingan jarak antara elektroda C1 dan PI dengan jarak antara P1 dan P2. Jika jarak antara elektroda potensial MN adalah a maka jarak antar elektroda arus (A dan B) adalah 2na+ a. Berikut adalah gambar untuk konfigurasi Wenner Schlumberger :

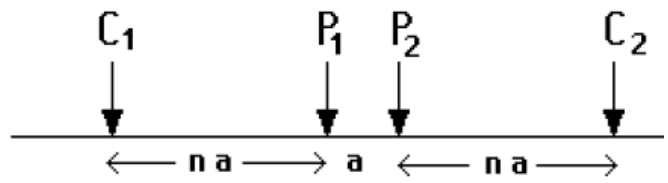

Gambar 2. Konfigurasi Wenner-Schlumberger (Loke, 1999). 
Faktor geometri dari konfigurasi Wenner Sclumberger adalah :

$$
\mathrm{k}=\mathrm{n}(\mathrm{n}+1) \pi \mathrm{a}
$$

\section{Resistivitas Batuan}

Setiap batuan mempunyai daya hantar listrik dan tahanan jenis tertentu. Batuan yang sama belum tentu mempunyai tahanan jenis yang sama dan sebaliknya harga tahanan jenis yang sama bisa dimiliki oleh batuan berbeda Hal ini terjadi karena nilai resistivitas atau tahanan jenis batuan memiliki rentang nilai yang bisa saling tumpang tindih. Berikut adalah tabel resistivitas batuan :

Tabel 1. Resistivitas Batuan Beku dan Metamorf (Telford, dkk., 1976).

\begin{tabular}{|c|c|}
\hline Rock Type & Resistivity Range $(\Omega \mathrm{m})$ \\
\hline Granite & $3 \times 10^{2}-10^{6}$ \\
\hline Granite Porphyry & $4.5 \times 10^{3}$ (wet) $-1.3 \times 10^{6}$ \\
\hline Feldspar Porphyry & (dry) \\
\hline Albite & $4 \times 10^{3}$ (wet) \\
\hline Syenite & $3 \times 10^{2}$ (wet) $-3.3 \times 10^{3}$ \\
\hline Diorit & (dry) \\
\hline Diorit Porphyry & $10^{2}-10^{6}$ \\
\hline Porphyryte & $10^{4}-10^{5}$ \\
\hline Carbonatized Porphyry & $1.9 \times 10^{3}$ (wet) $-2.8 \times 10^{4}$ \\
\hline Quartz Porphyry & (dry) \\
\hline Quartz Diorite & $10-5 \times 10^{4}$ (wet) $-3.3 \times 10^{3}$ \\
\hline Porphyry (Various) & (dry) \\
\hline Dacite & $2.5 \times 10^{3}$ (wet) $-6 \times 10^{4}$ \\
\hline Andesite & (dry) \\
\hline Diabase Porphyry & $3 \times 10^{2}-9 \times 10^{5}$ \\
\hline Diabase (various) & $2 \times 10^{4}-2 \times 10^{6}$ (wet) -1.8 \\
\hline Lavas & $\times 10^{5}$ (dry) \\
\hline Gabbro & $60-10^{4}$ \\
\hline Basalt & $2 \times 10^{4}$ (wet) \\
\hline Olivine Norite & $4.5 \times 10^{4}$ (wet) $-1.7 \times 10^{5}$ \\
\hline Peridotite & (dry) \\
\hline Hornfels & $10^{3}$ (wet) $-1.7 \times 10^{5}$ (dry) \\
\hline Schists (calcareous and & $20-5 \times 10^{7}$ \\
\hline mica) & $10^{2}-5 \times 10^{4}$ \\
\hline Tuffs & $10^{3}-10^{6}$ \\
\hline Graphite Schist & $10-1.3 \times 10^{7}$ (dry) \\
\hline Slates (various) & $10^{3}-6 \times 10^{4}$ (wet) \\
\hline Gneiss (various) & $3 \times 10^{3}$ (wet) $-6.5 \times 10^{3}$ \\
\hline Marble & (dry) \\
\hline Skarn & $8 \times 10^{3}$ (wet) $-6 \times 10^{7}$ (dry) \\
\hline
\end{tabular}

\begin{tabular}{|l|c|}
\hline Quarzites (various) & $20-10^{4}$ \\
$2 \times 10^{3}$ (wet) $-10^{5}$ (dry) \\
$10-10^{2}$ \\
$6 \times 10^{2}-4 \times 10^{7}$ \\
$6.8 \times 10^{4}$ (wet) $-3 \times 10^{6}$ \\
(dry) \\
$10^{2}-2.5 \times 10^{8}(\mathrm{dry})$ \\
$2.5 \times 10^{2}$ (wet) $-2.5 \times 10^{8}$ \\
(dry) \\
$10-2 \times 10^{8}$
\end{tabular}

Tabel 2. Resistivitas Batuan Sedimen (Telford, dkk., 1976).

\begin{tabular}{|c|c|}
\hline Rock Type & $\begin{array}{c}\text { Resistivity Range } \\
(\mathbf{\Omega m})\end{array}$ \\
\hline Consolidated Shales & $20-2 \times 10^{3}$ \\
Argillites & $10-8 \times 10^{2}$ \\
Conglomerates & $2 \times 10^{3}-10^{4}$ \\
Sandstones & $1-6.4 \times 10^{8}$ \\
Limestones & $50-10^{7}$ \\
Dolomite & $3.5 \times 10^{2}-5 \times 10^{3}$ \\
Unconsolidated Wet Clay & 20 \\
Marls & $3-70$ \\
Clays & $1-100$ \\
Alluvium and Sands & $10-800$ \\
Oil Sands & -800 \\
\hline
\end{tabular}

\section{Tanah Longsor dan Cracks}

Longsor adalah gerakan massa batuan induk dan lapisan-lapisan tanah pada bagian lereng atas dengan kemiringan landai sampai sangat curam ke arah kaki lereng sebagian akibat terlampauinya keseimbangan daya tahan lerengnya. Pergerakan tanah dapat diketahui dengan tanda-tanda seperti munculnya retak tarik dan kerutan di permukaan lereng, miringnya pepohonan, hilangnya kelurusan fondasi bangunan dan lainnya (Hardiyatmo, 2012).

Cracks (retakan) adalah suatu bidang diskontinuitas pada batuan yang dapat diinterpretasikan sebagai hasil dari suatu deformasi. Menurut Mochtar (2010) salah satu penentu kestabilan lereng adalah adanya fenomena cracks berupa retakan yang terjadi pada permukaan, ataupun akibat adanya pergerakan massa tanah pada masa lampau. Apabila infiltrasi air hujan lebih besar dari air yang keluar dari dalam lereng, maka akan terjadi water pressure built-up 
pada bidang retakan. Berikut adalah ilustrasi rembesan di dalam lereng :

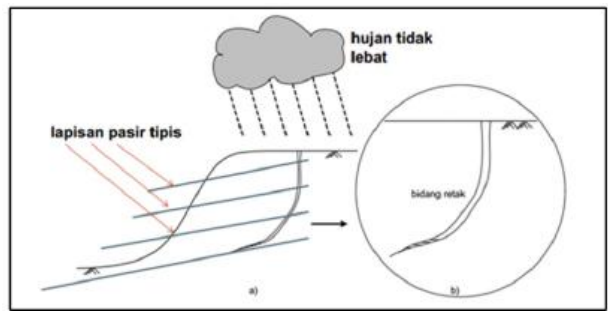

Gambar 3. Proses Rembesan Air Hujan pada Lereng (Mochtar, 2011).

\section{METODOLOGI PENELITIAN}

Lokasi penelitian ini berada di Dusun Dawung, Desa Olak-Alen, Kecamatan Selorejo, Blitar. Lokasi penelitian pernah terjadi peristiwa longsor 3 kali yang berada disisi Barat jalan. Berikut adalah desain akuisisi :

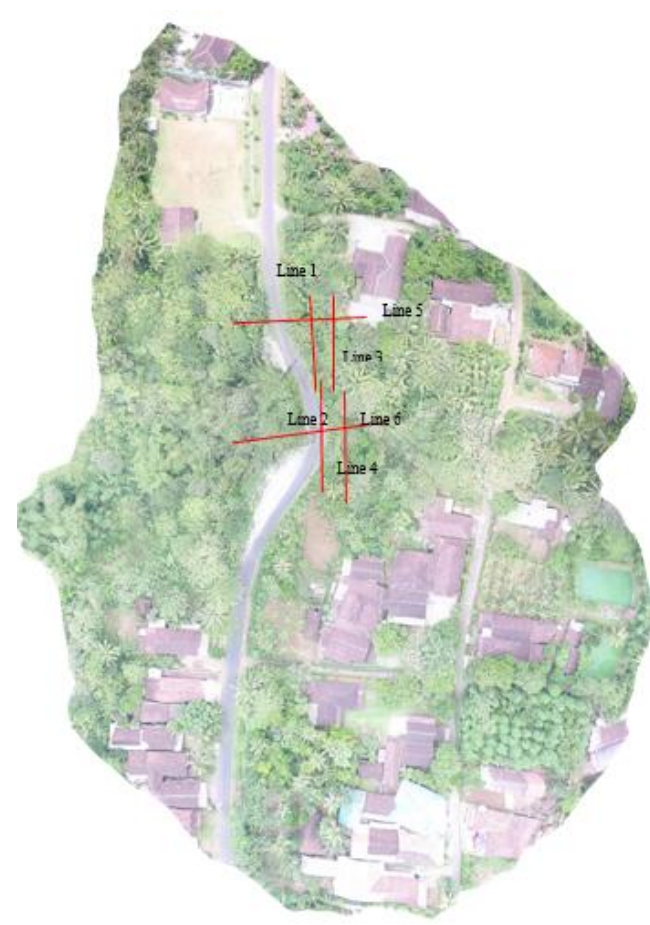

Gambar 4. Lokasi Penelitian yang Berada Di Garis Merah.

Pengambilan data yang dilakukan pada tanggal 26 November-8 Desember 2016. Data yang dihasilkan dari pengambilan data merupakan data resistivitas yang kemudian dilakukan pengolahan.
Pengambilan data dilakukan sebanyak dua kali yaitu sebelum dan setelah hujan lebat.

\section{HASIL DAN PEMBAHASAN \\ Analisa Letak Cracks}

Setelah dilakukan pengolahan pada setiap line yang ada, didapatkan letak cracks yang diindikasikan dengan penampang resistivitas yang rendah yang terakumulasi pada zona jenuh air. Cracks yang ada pada lereng berukuran sangat kecil, sehingga penampang resistivitas tidak dapat terlihat dengan jelas. Berikut adalah penampang resistivitas pada line pengukuran sebelum hujan :

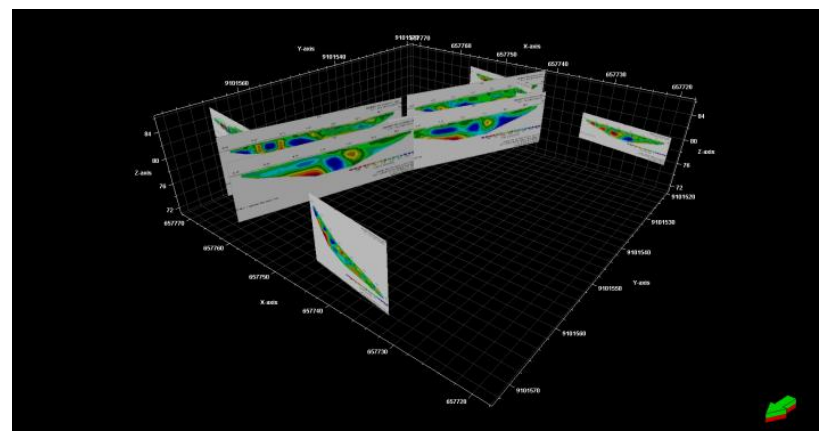

Gambar 5. Penampang Resistivitas Sebelum Hujan (Seluruh Line Pengukuran)

Terjadi perbedaan persebaran nilai resistivitas pada hasil pengolahan sebelum dan setelah hujan. Berikut adalah hasil penampang pada masing masing line pengukuran :

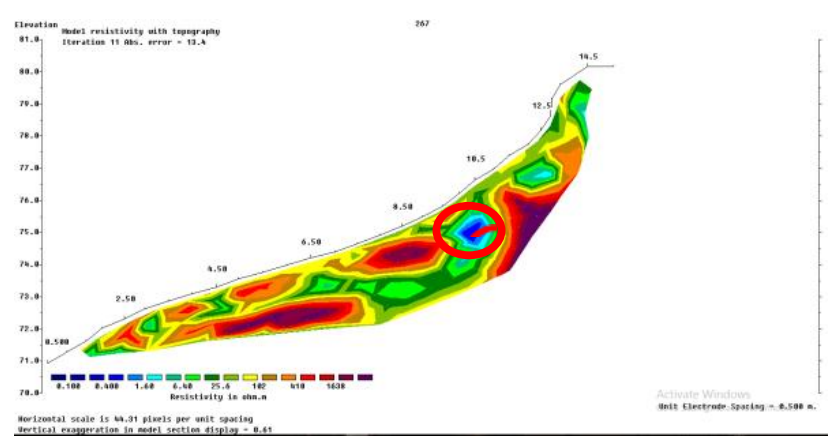

Gambar 6. Penampang Line 5 sebelum Hujan. 


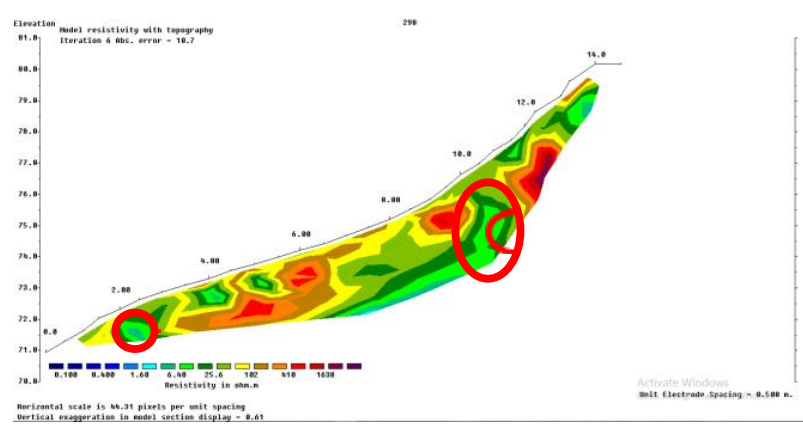

Gambar 7. Penampang Line 5 setelah Hujan.

Pada kedua penampang tersebut, terlihat zona yang memiliki saturasi air tinggi pada mulanya berada pada jarak 10 dengan kedalaman 2 meter. namun, ketika pengukuran dilakukan setelah hujan, cebakan air menghilang dan nilai resistivitas pada rentang nilai $20 \Omega \mathrm{m}$ meningkat. Hal ini disebabkan material top soil tererosi. Selain itu, pada meter ke 2, cebakan air mulai terbentuk kembali. Cracks pada daerah ini terlihat dipermukaan sebagai berikut ini :

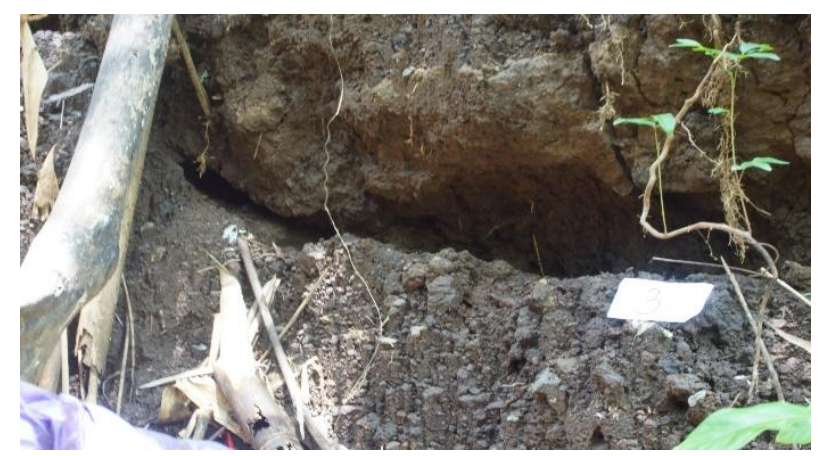

Gambar 8. Cracks pada Meter Ke 2 Line 5.

Cracks yang terlihat pada permukaan tersebut memiliki arah Utara-Selatan dengan panjang 3 meter lebar $15 \mathrm{~cm}$. Lintasan pengukuran pada line 5 berarah Barat - Timur, sehingga dapat diketahui penjalaran cracks yang berada di bawah permukaan.

\section{PENUTUP}

\section{Kesimpulan}

Kesimpulan yang didapat dari penelitian ini antara lain :

1. Terjadi perubahan distribusi nilai resistivitas pada daerah yang memiliki cracks.

2. Penjalaran cracks dari penampang memiliki arah Barat-Timur dengan kedalaman sekitar $3 \mathrm{~m}$.

3. Litologi yang mendominasi pada daerah penelitian adalah lempung yang memiliki nilai resistivitas sekitar $1-30 \mathrm{~m}$.

\section{Saran}

Saran untuk penelitian ini adalah :

1. Perlu dilakukan pemetaan secara rinci terhadap letak cracks yang terlihat di permukaan.

2. Untuk mendapatkan hasil yang lebih detil, spasi pengukuran dapat dibuat lebih rapat dan dapat dibuktikan dengan hasil pengeboran

\section{Ucapan Terima Kasih}

Penulis mengucapkan terima kasih kepada para dosen pembimbing Pak Widya Utama dan Mas Juan Pandu atas ide penulisan dan pengarahannya selama proses penelitian hingga penulisan.

\section{DAFTAR PUSTAKA}

Dwikorita ,Karnawati. 2005. Bencana Alam Gerak Massa Tanah di Indonesia dan Upaya Penanggulangannya. Yogyakarta: Universitas Gajah Mada.

Hardiyatmo, H.C., 2012 Penanganan Tanah Longsor dan Erosi. Gadjah Mada University Press, Yogyakarta

Loke, M.H., 2000. Electrical Imaging Surveys For Environmental and Engineering Studies.

Mochtar, Indrasurya B., 2011. Investigasi Longsoran Bagian Belakang Kantor Walikota Kota Bontang, Kalimantan Timur. Laporan Penyelidikan oleh Lembaga Penelitian dan Pengabdian kepada Masyarakat LPPM, ITS, untuk Pemda Kota Bontang.

Peta Geologi Indonesia Lembar Blitar, 1992.

Peta Wilayah Potensi Gerakan Tanah di Provinsi Jawa Timur Bulan September 2016. Kementerian Energi Dan Sumber Daya Mineral Republik Indonesia. 
Rahmawati, Arifah., 2009. Pendugaan Bidang Gelincir Tanah Longsor Berdasarkan Sifat Kelistrikan Bumi dengan Aplikasi Geolistrik Metode Tahanan Jenis Konfigurasi Schlumberger (Studi Kasus di Daerah Karangsambung dan Sekitarnya, Kabupaten Kebumen). Skripsi. Semarang: Fakultas FMIPA Unnes.

Telford, W.M., L.P. Geldart, , R.E. Sheriff, dan D.A. Keys., 1982. Applied Geophysic. London : Cambridge University Press.

Vernes., 1978. Slope Movement Types and Processes. In: Schuster RL, Krizek RJ (eds) Landslides, Analysis and Control, Special Report 176: Transportation Research Board, National Academy of Sciences, Washington DC, pp. 11. 